\title{
Skin prick testing in patients using beta-blockers: a retrospective analysis
}

Irene N Fung ${ }^{1}$, Harold L Kim ${ }^{1,2^{*}}$

\begin{abstract}
Rationale: The use of beta-blockers is a relative contraindication in allergen skin testing yet there is a paucity of literature on adverse events in this circumstance. We examined a population of skin tested patients on betablockers to look for any adverse effects.

Methods: Charts from 2004-2008 in a single allergy clinic were reviewed for any patients taking a beta-blocker when skin tested. Data was examined for skin test reactivity, type of skin test, concomitant asthma diagnosis, allergens tested, and adverse events.
\end{abstract}

Results: One hundred and ninety-one patients were taking beta-blockers when skin testing occurred. Seventy-two patients had positive skin tests. No tests resulted in an adverse event.

Conclusions: This data demonstrates the relative safety of administrating of skin prick tests to patients on betablocker treatment. Larger prospective studies are needed to substantiate the findings of this study.

\section{Introduction}

Beta antagonists, commonly known as beta-blockers, are a commonly prescribed class of medications. Beta-blockers are used in the treatment of congestive heart failure, coronary heart disease, cardiac arrhythmia, hypertension, tremor, glaucoma, and migraine headache. Importantly, beta-blockers significantly reduce both morbidity and mortality rates in congestive heart failure, in acute coronary syndrome, and post myocardial infarction [1-3]. However, beta-blockade may place atopic subjects at an increased risk of an anaphylactic reaction. Case reports suggest that when systemic allergic reactions occur secondary to immunotherapy, drugs, foods, and insects stings, they may be of greater severity in patients taking beta-blockers [4-11].

Due to the potential of beta-blockers to amplify the effects of anaphylaxis, these drugs are relatively contraindicated during allergy skin testing. The American Academy of Allergy Asthma \& Immunology (AAAAI) outlines this in its position statement, stating that "Systemic reactions to skin testing are rare. Nevertheless, special precautions, when these are appropriate, should be taken when the patient who needs sensitivity testing

\footnotetext{
* Correspondence: hlkim_kw@yahoo.ca

${ }^{1}$ McMaster University, Hamilton, Ontario, Canada
}

for IgE-mediated disease cannot stop treatment with a beta-blocking agent [12]." However, in our literature review on the topic, no case reports or prospective studies report adverse events in patients on beta-blockers who underwent skin testing. This retrospective study investigates whether there is any increased risk of anaphylaxis in patients who were allergy skin tested while they continued on a beta-blocker medication.

\section{Methods}

Charts of all patients seen at an allergy clinic in Kitchener, Ontario from 2004 and 2008 were searched for any beta-blocker use at the time of their clinic visit. These records were examined to identify if any individuals who were skin tested, while they continued to take beta-blockers, had any reactions to the skin testing. The charts of the patients who were found to be allergic, based on skin testing, were further analysed regarding the medical history, type of beta-blocker taken and skin test findings.

\section{Results}

One hundred and ninety-one patients were identified to be taking beta-blockers while undergoing skin testing. From the review of their charts, none of these patients experienced any adverse event secondary to skin testing. 
Specifically, there were no cases of anaphylaxis in these patients. Also, all patients who were taking beta-blockers at the time of the allergy consultation were skin tested.

Seventy-two patients on beta-blockers had positive results on skin testing, thus demonstrating an IgEmediated sensitivity. The mean age of these patients was 60 (range 34-89), and 58\% of these patients were male. Some other demographic data for the patients with positive skin test results is reported in Table 1. A few patients had more than one primary reason for referral. Spirometry findings and concomitant medications are also presented in the table as these two factors could have affected the severity of an anaphylactic reaction. Fifteen of the 72 allergic patients also had spirometry testing completed because they had some clinical history of respiratory symptoms. Two of the 15 had an obstructive pattern on their spirometry, as indicated by having a FEV1/FVC $<75 \%$ predicted. One patient was taking cetirizine and another was taking amitriptyline at the time of skin testing. These medications may have blunted the skin test response. Other common concomitant medications included HMG-CoA reductase inhibitors, diuretics, acetylsalicylic acid, angiotensin converting enzyme inhibitors, and calcium channel blockers.

The types of beta-blockers taken by the 72 patients with positive skin findings are summarized in table 2 . The majority of patients were on oral agents, with atenolol and propanolol being the most commonly used. Two patients were taking ocular topical beta-blocking agents. Table 3 shows the indications for beta-blocker use. A few patients had more than one indication documented in their charts.

The allergens the 72 allergic patients tested positive to are listed in table 4 . The majority of positive reactions were to environmental aeroallergens and insect venoms, but some patients were found to be allergic to latex, foods and penicillin.

\section{Discussion}

Beta-blockers are relatively contraindicated in both skin testing and immunotherapy for three reasons. They may: 1) worsen anaphylaxis severity; 2) make treatment of anaphylaxis more difficult; and 3) increase the incidence of anaphylaxis itself. First, in terms of anaphylaxis severity, beta-blockers can increase synthesis and release

Table 1 Characterization of Atopic Patients Assessed ( $\mathbf{N}=\mathbf{7 2}$ )

\begin{tabular}{|c|c|c|}
\hline & & n (\%) \\
\hline \multicolumn{3}{|l|}{ Reason for referral } \\
\hline & General allergy assessment & $34(47)$ \\
\hline & Environmental allergies & $13(18)$ \\
\hline & Rhinitis or sinusitis & $7(10)$ \\
\hline & Anaphylactic event & $5(7)$ \\
\hline & Rash or urticaria & $5(7)$ \\
\hline & Food allergy & $4(6)$ \\
\hline & Asthma & $4(6)$ \\
\hline & Angioedema & $3(4)$ \\
\hline & Cough & $3(4)$ \\
\hline & Drug allergy & $2(3)$ \\
\hline \multirow[t]{3}{*}{ Spirometry performed } & & $15(21)$ \\
\hline & FEV1\% $<80 \%$ predicted & $3(4)$ \\
\hline & FEV1/FVC $\%<75 \%$ predicted & $2(13)$ \\
\hline \multicolumn{3}{|l|}{ Other medications } \\
\hline & HMG-CoA reductase inhibitor linhibitors inhibitors & $22(31)$ \\
\hline & Diuretic & $19(26)$ \\
\hline & ASA & $18(25)$ \\
\hline & ACEi & $14(19)$ \\
\hline & $\mathrm{CCB}$ & $10(14)$ \\
\hline & Amitriptyline & $1(1)$ \\
\hline & Cetirizine & $1(1)$ \\
\hline
\end{tabular}


Table 2 Assessment of beta-blockers used by patients ( $N$ $=72$ )

\begin{tabular}{lll}
\hline & & $\mathrm{n}(\%$ patients) \\
\hline Beta-blocker route & & \\
\hline & Oral & $70(97)$ \\
\hline Beta-blocker name & Ocular & $2(3)$ \\
\hline & & \\
\hline & Atenolol & $42(58)$ \\
\hline & Metoprolol & $15(21)$ \\
\hline Nadolol & $4(6)$ \\
\hline & Acebutalol & $4(6)$ \\
\hline & Propanolol & $2(3)$ \\
\hline & Bisprolol & $2(3)$ \\
\hline Timolol & $1(1)$ \\
\hline & Labetolol & $1(1)$ \\
\hline
\end{tabular}

of anaphylactic mediators $[13,14]$, as well as enhance responsiveness of organs to the mediators released [15-18]. In atopic subjects, total IgE production may increase. Those with allergic asthma already have excessive alpha-adrenergic reactivity and beta-blockade may further exacerbate this problem. In the treatment of anaphylaxis, beta-blockade has been shown to blunt the effect of epinephrine in animal and human models [19-22]. Finally, in case reports of patients with severe anaphylactic reactions, several patients were coincidently on beta-blocker medications [23-29].

While all of the issues above concerning beta-blockers and anaphylaxis are important, we argue that with allergy skin prick testing and intradermal testing with insect venoms and penicillin, the risk of anaphylaxis is so low that testing can be completed safely on most patients taking beta-blockers. Our study failed to show any adverse events in patients undergoing skin testing while taking beta-blockers. Because systemic reactions to skin testing are so uncommon, larger prospective studies comparing patients who are taking and not taking beta-blockers should be performed to prove any risk of beta-blocker use. It is important to note that fatalities from skin testing regardless of beta-blocker use are

Table 3 Indications for beta-blocker use $(\mathbf{N}=72)$

\begin{tabular}{ll}
\hline HTN & $\mathbf{n}(\%)$ \\
\hline CAD & $49(68)$ \\
\hline Ml & $17(24)$ \\
\hline Headache & $7(10)$ \\
\hline Glaucoma & $2(3)$ \\
\hline Arrhythmia & $2(3)$ \\
\hline Tremor & $2(3)$ \\
\hline
\end{tabular}

HTN = hypertension, $\mathrm{CAD}=$ coronary artery disease, $\mathrm{MI}=$ myocardial infarction
Table 4 Positive skin tests $(\mathbf{N}=72)$

\begin{tabular}{ll}
\hline & Number positive (\%) \\
\hline Ragweed & $25(35)$ \\
\hline Tree & $24(33)$ \\
\hline Grass & $24(33)$ \\
\hline Mold & $22(31)$ \\
\hline Dust mite & $22(31)$ \\
\hline Cat & $15(21)$ \\
\hline Yellow jacket* & $15(21)$ \\
\hline Wasp* & $11(15)$ \\
\hline Yellow hornet* & $10(14)$ \\
\hline White faced hornet* & $9(13)$ \\
\hline Dog & $7(10)$ \\
\hline Guinea pig & $3(4)$ \\
\hline Seafood & $3(4)$ \\
\hline Hamster & $2(3)$ \\
\hline Fruit & $2(3)$ \\
\hline Latex & $2(3)$ \\
\hline Nut & $2(3)$ \\
\hline Horse & $1(1)$ \\
\hline Vegetable & $1(1)$ \\
\hline Penicillin* & $1(1)$ \\
\hline Honeybee* & $1(1)$ \\
\hline
\end{tabular}

*Intradermally tested

extremely rare. Through a national questionnaire study with members of the American Academy of Allergy and Immunology, seven fatalities are known: two occurring in 1964, four between 1980-1983, and one in a more recent report surveying the period between 1990-2001 [30-32]. None of these patients were known to be using beta-blockers. Furthermore, we could not find any published reports identifying any life-threatening or fatal reactions when patients taking beta-blockers were skin prick tested. In contrast, there are 88 reports from the American Academy of Allergy and Immunology over this time of allergen immunotherapy fatalities, with 3 of these patients taking beta-blockers [33-35]. Thus, while there may be an increased risk of anaphylaxis in patients on beta-blockers undergoing immunotherapy, the degree of risk is likely smaller in patients undergoing allergy skin testing. Of course, standard safety measures should still be available in the clinics where skin testing is being performed.

This study provides information regarding the safety of skin prick testing in patients taking beta-blocker medications. To date, this is the first study known which assesses this issue specifically. Our retrospective study showed no adverse effects of skin testing in 191 patients on beta-blockers. The fact that 72 patients with positive skin tests were able to tolerate the skin testing without any problems suggests skin testing is likely a 
safe procedure in most patients on beta-blockers. However, large multi-center prospective studies are required to truly measure any increased risk of anaphylaxis of allergy skin testing in patients taking beta-blockers. Until these larger studies are performed, skin testing should still be performed with caution in patients taking beta-blocker medications.

\section{Acknowledgements}

We wish to acknowledge Dr. David Fischer for his help in reviewing this paper.

\section{Author details}

McMaster University, Hamilton, Ontario, Canada. ${ }^{2}$ University of Western

Ontario, London, Ontario, Canada.

\section{Authors' contributions}

IF helped to design the study, collected the data for analysis and wrote the paper. HK conceived the study and participated in its design and writing. All authors read and approved the final manuscript.

\section{Competing interests}

The authors declare that they have no competing interests.

Received: 11 December 2009

Accepted: 20 January 2010 Published: 20 January 2010

\section{References}

1. Foody JM, Farrell MH, Krumholz HM: Beta-Blocker Therapy In Heart Failure: Scientific Review. JAMA 2002, 287(7):883-889.

2. Yusef SPRLCRSP: Beta Blockade During And After Myocardial Infarction: An Overview Of The Randomized Trials. Prog Cardiovasc Dis 1985, 27(5):335-371.

3. Freemantle N, Cleland J, Young P, Mason J, Harrison J: Beta Blockade After Myocardial Infarction: Systematic Review And Meta Regression Analysis. BMJ 1999, 318(7200):1730-1737.

4. Momeni M, Brui B, Baele P, Matta A: Anaphylactic Shock In A Beta-Blocked Child: Usefulness Of Isoproterenol. Paediatr Anaesth 2007, 17(9):897-899.

5. Jacobs RL, Rake Gw Jr, Fournier Dc, Chilton RJ, Culver WG, Beckmann CH: Potentiated Anaphylaxis In Patients With Drug-Induced Beta-Adrenergic Blockade. J Allergy Clin Immunol 1981, 68(2):125-127.

6. Newman BR, Schultz LK: Epinephrine-Resistant Anaphylaxis In A Patient Taking Propranolol Hydrochloride. Ann Allergy 1981, 47(1):35-37.

7. Hannaway PJ, Hopper GD: Severe Anaphylaxis And Drug-Induced BetaBlockade. N Engl J Med 1983, 308(25):1536.

8. Awai LE, Mekori YA: Insect Sting Anaphylaxis And Beta-Adrenergic Blockade: A Relative Contraindication. Ann Allergy 1984, 53(1):48-49.

9. Ingall $M$, Goldman $G$, Page LB: Beta-Blockade In Stinging Insect Anaphylaxis. JAMA 1984, 251(11):1432.

10. Berkelman RL, Finton RJ, Elsea WR: Beta-Adrenergic Antagonists And Fatal Anaphylactic Reactions To Oral Penicillin. Ann Intern Med 1986, 104(1):134

11. Stark BJ, Sullivan TJ: Biphasic And Protracted Anaphylaxis. J Allergy Clin Immunol 1986, 78(1 Pt 1):76-83.

12. American Academy Of Allergy Asthma \& Immunology: Academy Position Statement: Adrenergic Blockers, Allergen Immunotherapy And Skin Testing. AAAAl Media Center 2002http:/Nww.Aaaai.Org/Members/ Academy_Statements/Position_Statements/Blockers_Immuno_Skin.Asp, [Cited 8 A.D. Nov 7].

13. Kaplan AP, Anderson JA, Valentine MD, Lockey RF, Pierson WE, Zweiman B, et al: Beta-Adrenergic Blockers, Immunotherapy, And Skin Testing. American Academy Of Allergy And Immunology. J Allergy Clin Immunol 1989, 84(1):129-130.

14. Mjorndal TO, Chesrown SE, Frey MJ, Reed BR, Lazarus SC, Gold WM: Effect Of Beta-Adrenergic Stimulation On Experimental Canine Anaphylaxis In Vivo. J Allergy Clin Immunol 1983, 71(1 Pt 1):62-70.

15. Shereff RH, Harwell W, Lieberman $\mathrm{P}$, Rosenberg EW, Robinson $\mathrm{H}$ : Effect Of Beta Adrenergic Stimulation And Blockade On Immediate
Hypersensitivity Skin Test Reactions. J Allergy Clin Immunol 1973, 52(6):328-333

16. Nisam MR, Zbinden A, Chesrown S, Barnett D, Gold WM: Distribution Of And Pharmacological Release Of Histamine In Canine Lung In Vivo. $J$ Appl Physiol 1978, 44(3):455-463.

17. Matsumura Y, Tan EM, Vaughan JH: Hypersensitivity To Histamine And Systemic Anaphylaxis In Mice With Pharmacologic Beta Adrenergic Blockade: Protection By Nucleotides. J Allergy Clin Immunol 1976, 58(3):387-394.

18. Matsumura $Y$, Tan EM, Vaughan JH: Histamine Hypersensitivity In Mice Induced By Bordetella Pertussis Or Pharmacologic Beta Adrenergic Blockade. Effects Of Adrenergic, Cholinergic, And Other Drugs. J Allergy Clin Immunol 1976, 58(3):395-404.

19. Kim Y: Interaction Between Beta Blockers And Epinephrine On Hemodynamics Of Spontaneously Hypertensive Rats. Res Commun Chem Pathol Pharmacol 1993, 80(1):3-19.

20. Matsumura Y, Tan EM, Vaughan JH: Hypersensitivity To Histamine And Systemic Anaphylaxis In Mice With Pharmacologic Beta Adrenergic Blockade: Protection By Nucleotides. J Allergy Clin Immunol 1976, 58(3):387-394.

21. Forfang K, Simonsen S: Effects Of Atenolol And Pindolol On The Hypokalaemic And Cardiovascular Responses To Adrenaline Infusion. Eur J Clin Pharmacol 1989, 37(1):23-27.

22. Raptis S, Rosenthal J, Welzel D, Moulopoulos S: Effects Of Cardioselective And Non-Cardioselective Beta-Blockade On Adrenaline-Induced Metabolic And Cardiovascular Responses In Man. Eur J Clin Pharmacol 1981, 20(1):17-22.

23. Momeni M, Brui B, Baele P, Matta A: Anaphylactic Shock In A Beta-Blocked Child: Usefulness Of Isoproterenol. Paediatr Anaesth 2007, 17(9):897-899.

24. Jacobs RL, Rake GW Jr, Fournier DC, Chilton RJ, Culver WG, Beckmann CH: Potentiated Anaphylaxis In Patients With Drug-Induced Beta-Adrenergic Blockade. J Allergy Clin Immunol 1981, 68(2):125-127.

25. Newman BR, Schultz LK: Epinephrine-Resistant Anaphylaxis In A Patient Taking Propranolol Hydrochloride. Ann Allergy 1981, 47(1):35-37.

26. Hannaway PJ, Hopper GD: Severe Anaphylaxis And Drug-Induced BetaBlockade. N Engl J Med 1983, 308(25):1536.

27. Awai LE, Mekori YA: Insect Sting Anaphylaxis And Beta-Adrenergic Blockade: A Relative Contraindication. Ann Allergy 1984, 53(1):48-49.

28. Ingall $M$, Goldman $G$, Page LB: Beta-Blockade In Stinging Insect Anaphylaxis. JAMA 1984, 251(11):1432.

29. Berkelman RL, Finton RJ, Elsea WR: Beta-Adrenergic Antagonists And Fatal Anaphylactic Reactions To Oral Penicillin. Ann Intern Med 1986, 104(1):134

30. Lockey RF, Benedict LM, Turkeltaub PC, Bukantz SC: Fatalities From Immunotherapy (IT) And Skin Testing (ST). J Allergy Clin Immunol 1987, 79(4):660-677.

31. Reid MJ, Lockey RF, Turkeltaub PC, Platts-Mills TA: Survey Of Fatalities From Skin Testing And Immunotherapy 1985-1989. J Allergy Clin Immunol 1993, 92(1 Pt 1):6-15.

32. Bernstein DI, Wanner M, Borish L, Liss GM: Twelve-Year Survey Of Fatal Reactions To Allergen Injections And Skin Testing: 1990-2001. J Allergy Clin Immunol 2004, 113(6):1129-1136.

33. Lockey RF, Benedict LM, Turkeltaub PC, Bukantz SC: Fatalities From Immunotherapy (IT) And Skin Testing (ST). J Allergy Clin Immunol 1987 79(4):660-677.

34. Reid MJ, Lockey RF, Turkeltaub PC, Platts-Mills TA: Survey Of Fatalities From Skin Testing And Immunotherapy 1985-1989. J Allergy Clin Immunol 1993, 92(1 Pt 1):6-15.

35. Bernstein DI, Wanner M, Borish L, Liss GM: Twelve-Year Survey Of Fatal Reactions To Allergen Injections And Skin Testing: 1990-2001. J Allergy Clin Immunol 2004, 113(6):1129-1136.

doi:10.1186/1710-1492-6-2

Cite this article as: Fung and Kim: Skin prick testing in patients using beta-blockers: a retrospective analysis. Allergy, Asthma \& Clinical Immunology 2010 6:2 